\title{
Erratum to: Natural Volcanic Tuff-Based Geopolymer for Zn Removal: Adsorption Isotherm, Kinetic, and Thermodynamic Study
}

\author{
Kamel K. Al-Zboon • Bashar M. Al-smadi • \\ Sajedh Al-Khawaldh
}

Published online: 4 April 2017

(C) Springer International Publishing Switzerland 2017

\section{Erratum to: Water Air Soil Pollut \\ DOI 10.1007/s11270-016-2937-5}

In the original publication, all instances of "Chapazite" should have been "Chabazite". This appeared in section 3.1.1, twice in the 1 st paragraph, once in the 2 nd paragraph and once in Fig. 1 caption. Equation 14 should be corrected as shown below:

$\operatorname{Ln}(1-\theta)=\operatorname{Ln}\left(S^{*}\right)+\frac{E_{\mathrm{a}}}{\mathrm{RT}}$

The online version of the original article can be found at http://dx. doi.org/10.1007/s11270-017-3335-3

K. K. Al-Zboon $(\bowtie)$

Department of Environmental Engineering, Al-Huson University College, Al-Balqa Applied University, P.O. Box 50, Huson, Irbid 21510, Jordan

e-mail: alzboon@bau.edu.jo

B. M. Al-smadi · S. Al-Khawaldh Department of Civil Engineering Faculty of Engineering and Technology, University of Jordan, Amman, Jordan 